\title{
Effect of Dominant Versus Non-dominant Vision in Postural Control
}

\author{
Rae-Young Park, M.D. , Hoi-Sung Kee, M.D., Jung-Ho Kang, M.D., \\ Su-Jin Lee, M.D., Soe-Ra Yoon, M.D., Kwang-Ik Jung, M.D.
}

Department of Rehabilitation Medicine, Gwangju Veterans Hospital, Gwangju 506-702, Korea

Objective To assess the effect of dominant and non-dominant vision in controlling posture in quiet stance.

Method Twenty-five healthy elderly subjects aged over 60 years old and twenty-five young subjects aged under 30 years old were assessed by computerized dynamic posturography. Postural stability was measured in two conditions; dominant eye open and non-dominant eye open. We used the sensory organization test (SOT) for evaluating sensory impairment. A SOT assessed the subject's ability to use and integrate somatosensory input, vision, and vestibular cues effectively to maintain balance. The SOT was conducted 3 times, and the average value of the 3 trials was used for data analysis. Equilibrium scores reflected the subject's anteroposterior sway. The highest possible score was 100 , which indicated that the subject did not sway at all, and a score of 0 indicated a fall from the footplate. Determination of ocular dominance was performed by a hole-in-the card test.

Results For the twenty-five young subjects in this study, equilibrium score in two conditions did not differ. However, for elderly subjects over 60 years, the equilibrium score in dominant vision was higher than in nondominant vision $(\mathrm{p}<0.05)$.

Conclusion In young subjects, there were no significant differences in postural control between dominant vision and non-dominant vision. However, in elderly subjects, postural control in non-dominant vision was significantly impaired. Therefore, the evaluation of a dominant eye should be considered in rehabilitation programs for elderly people.

Key Words Postural control, Dominant vision, Non dominant vision, Balance, Elderly

\section{INTRODUCTION}

In pairs of organs found in both sides of the body, one is generally superior to the other. It is apparent in the hands and feet the same way as it is in the eyes. Koo and Cho ${ }^{1}$

Received May 18, 2010; Accepted January 3, 2011

Corresponding author: Soe-Ra Yoon

Department of Rehabilitation Medicine, Gwangju Veterans Hospital, 887-1, Sanwol-dong, Gwangsan-gu, Gwangju 506-702, Korea

Tel: +82-62-602-6295, Fax: +82-62-602-6990,E-mail: standupmd@ medicate.net

Copyright $\odot 2011$ by Korean Academy of Rehabilitation Medicine remarked the right eye tends to be dominant for normal persons, fixing eye is highly associated with dominant eye for strabismus patients, and dominant eye is related to eyesight.

Postural control ability to maintaining balance is essential for a successful daily life. ${ }^{2}$ Postural control process consist of interaction of signals from somatosensory, visual sensory system and vestibular system including proprioceptive sensory aspects. ${ }^{3}$ If any of the above elements is missing, a person is not able to maintain body balance. This creates fear of fall and in many cases leads to fracture by fall which ultimately restricts people 
from enjoying daily routine life. ${ }^{4}$

Visual sense provides information about the environmental form, hazardous situation, distance and ground condition on which movement occurs. It also provides body location, intensity and difficulty of movement for a person to perceive the situation and to adjust their posture. Together with a vestibular organ and proprioceptive sensory, it also helps a person to keep normal standing posture by regulating the central gravity above base of support in any given environment. ${ }^{5}$

Isotalo et al. ${ }^{6}$ did not find any statistically significant results when they evaluated the sense of balance by dividing one-eye watch and two-eye watch of 28 normal adults. They also measured the posture adjustment effect of both the dominant and non-dominant eye, but no significant difference was found. However, the above study was conducted on normal persons excluding elderly people who were under high danger of fall.

Accordingly, this study attempted to compare and analyze the balance control ability between elderly subjects and young adults using Balance Master ${ }^{\circledR}$ (NeuroCom ${ }^{\circledR}$, Oregon, USA), which was able to quantify body sway objectively, determine the location of central point of pressure, and evaluate postural control ability of the elderly by measuring the dominant or non-dominant eye, respectively.

\section{MATERIALS AND METHODS}

\section{Research subjects}

This study consisted of two groups: one group of 25 patients between 60 and 80 years old who were diagnosed with no abnormal findings in visual acuity test and fundus examination executed at the department of ophthalmology in the hospital and who had at least 0.7 maximum corrected eyesight, and the other group of 25 young adults between 20 and 29 years old. The participants all gave written consent.

\section{Research methodology}

The dominant eye test was conducted using the holein-the-card test as follows; the patients held a hole-inthe-card with both hands and observed the distant target through the hole of the card with two eyes open. Under that state, the dominant eye was determined by making each eye shut tight by turns. The dominant eye test was
Table 1. Six Conditions of Sensory Organization Test

\begin{tabular}{lcll}
\hline & $\begin{array}{c}\text { Force } \\
\text { platform }\end{array}$ & Eyes & Screen \\
\hline Condition 1 & Fixed & Open & Fixed \\
Condition 2 & Fixed & Closed & Fixed \\
\hline Condition 3 & Fixed & Open & Movement \\
Condition 4 & Sway & Open & Fixed \\
\hline Condition 5 & Sway & Closed & Fixed \\
\hline Condition 6 & Sway & Open & Movement \\
\hline
\end{tabular}

carried out both in short and long distance.

For balance test, Sensory Organization Test (SOT) was executed by using SMART Balance Master ${ }^{\circledR}$ system, which is available for qualifying evaluation. The participants were explained sufficiently about the research procedure the day before the testing day.

SMART Balance Master ${ }^{\circledR}$ system consists of two force platforms, a screen and a computer. The participants were set to stand on the center of force platform on bare feet with shoulder width, gazing at the front picture with two arms folded. The test began after one exercise to stabilize the posture. For SOT 6 total conditions - fix/ move of force platform, open eye/closed eye, and fix/ move of background platform - were applied for 20 seconds each to measure the sway of the pressure center of the body. Condition 1 was the state of the open eye on the fixed force platform and background platform, condition 2 was the state of closed eye on the fixed force platform and background platform, condition 3 was the state of open eye on the fixed force platform and moved background platform, condition 4 was the state of open eye on the moved force platform and fixed background form, condition 5 was the state of closed eye on the moved force platform and fixed background platform, and condition 6 was the state of open eye on the moved force platform and background platform (Table 1, Fig. 1). Each test was repeated three times. The sway measured before and after was expressed as the Equilibrium score (EQ), which was calculated by comparing with the normal range of 12.5 degree. $^{7}$ If the score was closer to 100 , balance control ability was excellent, and the average of $3 \mathrm{EQ}$ measurements was recorded. The 6 conditions were applied to both dominant eye and nondominant eye to be closed, respectively. 30 minutes of rest was given between the test to restore concentration 
1

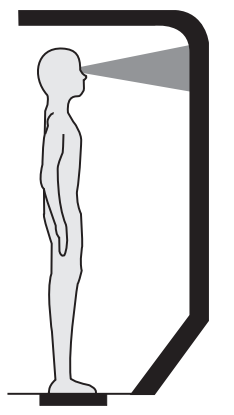

(1)

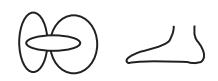

4

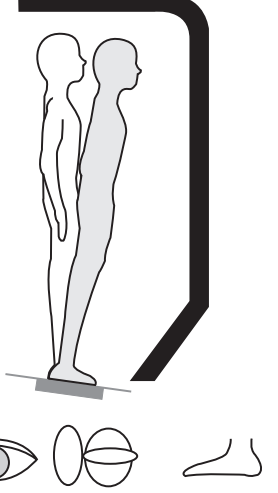

2

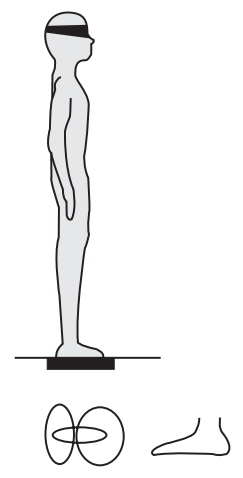

5

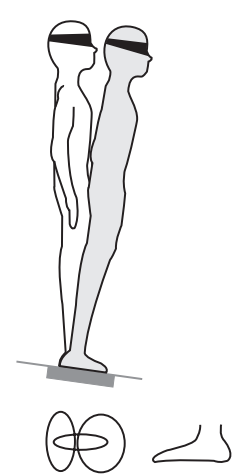

Sensory organization test
3

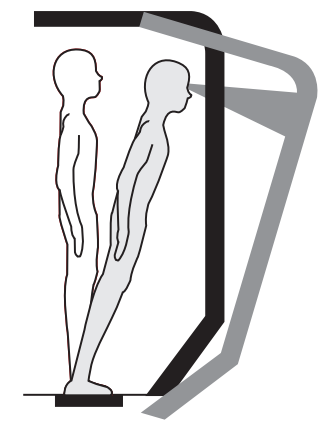

$\infty \theta<$

6

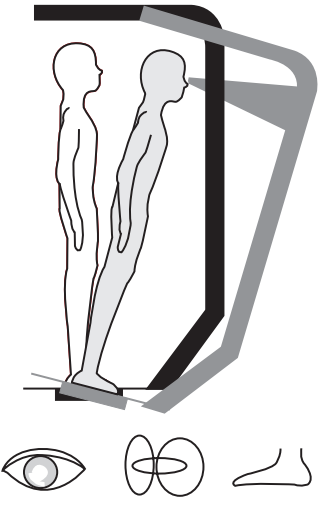

Fig. 1. Six conditions of sensory organization test (SOT).

Table 2. General Characteristics of the Subjects

and prevent fatigue.

The differences of EQ in both dominant eye group and non-dominant eye group of the young adult group and the aged group were compared and analyzed. Paired t-test was applied for statistical analysis, and statistical significance level was p-value less than 0.05 .

\section{RESULTS}

The general characteristics of the research subjects

The age range of young adults was between 20 and 29 years old, and their average age was 25.4. For the elderly, the range was between 60 and 80 years old with an average age of 66.07 . The average height was $170 \pm 4.8 \mathrm{~cm}$ and $158 \pm 9.3 \mathrm{~cm}$, respectively, and the average weight was $69.4 \pm 2.4 \mathrm{~kg}$ and $67.7 \pm 4.5 \mathrm{~kg}$, respectively (Table 2).

The comparison of the sense of balance between dominant eye and non-dominant eye

For the young adult group, no statistically significant difference in the sense of balance between dominant eye and non-dominant eye was detected under all 6 conditions (Table 3$)(\mathrm{p}>0.05)$.

\begin{tabular}{lcc}
\hline & $\begin{array}{c}\text { Younger } \\
\text { group }\end{array}$ & $\begin{array}{c}\text { Elderly } \\
\text { group }\end{array}$ \\
\hline Age (years) & $25.4 \pm 2.4$ & $66.07 \pm 5.3$ \\
\hline Sex & & \\
\hline Male & 20 & 20 \\
\hline Female & 5 & 5 \\
\hline Height $(\mathrm{cm})$ & $170 \pm 4.8$ & $158 \pm 9.3$ \\
\hline Body weight $(\mathrm{kg})$ & $69.4 \pm 2.4$ & $67.7 \pm 4.5$ \\
\hline Rt. Dominant eye subject & 3 & 2 \\
\hline
\end{tabular}

Values are mean \pm standard deviation

However, when the sense of balance between dominant eye and non-dominant eye for the aged was compared, the conditions 3,4 , and 6 showed a statistically significant difference while there was no significant difference in the conditions 1,2 and 5 (Table 3$)(\mathrm{p}<0.05)$.

\section{DISCUSSION}

The dominant eye concept was first introduced in $1593,{ }^{8}$ and was defined as a tendency to get visual sense 
Table 3. Equilibrium Score of the Subjects

\begin{tabular}{ccccc}
\hline \multirow{2}{*}{ Equilibrium score } & \multicolumn{2}{c}{ Younger group } & \multicolumn{2}{c}{ Elderly group } \\
\cline { 2 - 5 } & DV & NDV & DV & NDV \\
\hline Condition 1 & $91.54 \pm 3.28$ & $91.69 \pm 3.57$ & $80.8 \pm 6.16$ & $80.32 \pm 5.35$ \\
Condition 2 & $91.54 \pm 4.37$ & $91.62 \pm 4.37$ & $72.88 \pm 8.36$ & $73.56 \pm 6.46$ \\
Condition 3 & $89.23 \pm 4.48$ & $88.69 \pm 6.81$ & $78.72 \pm 10.11^{*}$ & $70.96 \pm 10.12$ \\
Condition 4 & $87.69 \pm 4.23$ & $86.69 \pm 6.22$ & $67.28 \pm 10.69^{*}$ & $62.64 \pm 10.91$ \\
Condition 5 & $74.38 \pm 7.48$ & $74.38 \pm 7.48$ & $61.12 \pm 9.47$ & $61.64 \pm 9.33$ \\
Condition 6 & $78.31 \pm 8.44$ & $78.31 \pm 8.64$ & $66.24 \pm 6.71^{*}$ & $63.04 \pm 6.52$ \\
\hline
\end{tabular}

Values are mean \pm standard deviation

NDV: Non dominant eye vision, DV: Dominant eye vision

${ }^{*} \mathrm{p}<0.05$ by Paired t-test: compared to NDV

information from the dominant eye rather than the nondominant eye for focus, attention and recognition., ${ }^{9,10}$ Dominant eye is generally known to be determined under the age of 3 , when no shortsightedness is developed. It is also likely to be determined hereditarily, ${ }^{11}$ and dominant eye can be so stable $e^{9}$ that no change is made unless the decline of eyesight of dominant eye becomes heavy. ${ }^{8}$

Dornan et al. ${ }^{12}$ reports that visual sensory ability takes greatest influence on the body posture and balance in the static state. Meanwhile, the sense of balance perceives the location shift of the head in accordance with the change of the surrounding environment and body, and it does not play an important role in maintaining sound posture and balance if the function of visual sense and intrinsic receptive capacity is fine. ${ }^{13}$

Posture control means to keep the center of gravity of the body within the support range and if an object stands on force platform using Balance Master ${ }^{\circledR}$ system, the center of vertical repulsive power (the center of gravity of the body) can be measured and the movement degree in this center of gravity becomes a barometer of stability. ${ }^{14}$ The two processes of perception control and movement control are required to place the center of gravity within the limit of balance. The first process is determined to perceive the location of the center of gravity affected by bearing surface and gravity. This process should be controlled by integrating three balancing senses of visual sense, vestibular system and somatosensory located in the skin, muscle and articulation. Here, the central nervous system resolves the confusion of sensation by accepting accurate sense and by dismissing inaccurate sense. For example, when the bearing surface is moved, the somatosensory should be ignored for its inaccuracy, and when the eyesight is moved, the information of visual sense becomes inaccurate. This confusing and perplexing sense that is of not help to perceiving information of balance is called sway referenced sensation. ${ }^{7}$ This study uses disequilibrium evaluation of the Balance Master ${ }^{\circledR}$ system in order to evaluate control ability of perception.

In 1996, when Liston et al studied the validity of the Balance Master ${ }^{\circledR}$ system, they remarked that the three static index and 6 dynamic index were significantly associated with Berg equilibrium barometer, and Ishizaki et al. ${ }^{15}$ argued that sway of posture had no relation with the number of repetitions in balance evaluation.

This study evaluated the balance capacity of dominant eye and non-dominant eye using Balance Master ${ }^{\circledR}$ system. When the balance ability of dominant eye and nondominant eye for the young adult group was compared, there was no statistically significant difference in EQ of all conditions. This result is consistent with that of Isotalo et al. ${ }^{6}$ However, balance ability was separately compared in the aged group and there was no statistically significant difference in conditions 1,2 and 5, but conditions 3 , 4 and 6 showed a statistically significant difference in balance ability. Conditions 3, 4 and 6 all included sway referenced sensation. There may be several causes of this. The fact that there was no difference in EQ between dominant eye and non-dominant eye under condition 1 with no sway referenced sensation can be considered to show compensation ability against the loss of function. For conditions 2 and 5, although the results must be identical as the tests were carried out with two eyes closed, some measurement error took place, but was insignificant. However, there was a difference in EQ for condition 3 with the visual sway referenced sensation, 
condition 4 with somatosensory sway referenced sensation and condition 6 with visual and somatosensory sway referenced sensation. This may be because the aged group had a high dependency on the dominant eye, especially the dependency on dominant eye in dealing with visual sway referenced sensation in the central nerve system compared with the young adults. This could also be because the compensation ability by non-dominant eye against the loss of function of dominant eye was declined when dominant eye was blocked. When sway referenced sensation was not included, the compensation by non-dominant eye against the loss of function of the dominant eye was made possible. However, in the case that sway referenced sensation was included, it appeared that proper compensation was not made.

It is natural that EQ was lower under condition 6 than condition 4 since condition 6 executed more perception control. However, the value change was higher for the young adult group than the aged group. Bottom effect of Balance Master ${ }^{\circledR}$ system might be the cause of this phenomenon. If EQ is evaluated without falling down during the actual test, it is impossible to measure any lower score.

Previous research showed that there was no statistically significant difference in balance ability between the dominant and non-dominant eye for young adults. ${ }^{6}$ While other current studies were on normal persons excluding the elderly people who were under high danger of fall, this study is meaningful in that it attempts to evaluate balance ability between the dominant and nondominant eye in aged people.

\section{CONCLUSION}

Using Balance Master ${ }^{\circledR}$ system, this study confirmed that the decline of balance ability for the elderly took place when they gazed with their non-dominant eye, compared with young adults. This study can be used as a base resource to prevent falling accidents of the aged. It is also anticipated to contribute to the rehabilitation of patients with optic nerve circuit damage due to hemispheric lesion or brain stem lesion, or visually damaged patients due to ocular or corneal defect, as well as contribute to the prevention of falling accidents and their treatment.

\section{REFERENCES}

1. Koo BS, Cho YA. The relationship of dominant eye, dominant hand, and deviated eye in strabismus. J Korean Ophthalmol Soc 1996; 37: 1277-1282

2. Cohen H, Blatchly CA, Gombash LL. A study of the clinical test of sensory interaction and balance. Phys Ther 1993; 73: 346-354

3. Di Fabio RP. Sensitivity and specificity of platform posturography for identifying patients with vestibular dysfunction. Phys Ther 1995; 75: 290-305

4. Hatch J, Gill-Body KM, Portney LG. Determinants of balance confidence in community-dwelling elderly people. Phys Ther 2003; 83: 1072-1079

5. Umphred DA. Neurological rehabilitation, 4th ed, St. Louis: Mosby, 2001, 616-660

6. Isotalo E, Kapoula Z, Feret PH, Gauchon K, Zamfirescu F, Gagey PM. Monocular versus binocular vision in postural control. Auris Nasus Larynx 2004; 31: 11-17

7. Goh EK. Clinical application of computerized dynamic posturography. Res Vestibul Sci 2005; 4: 107118

8. Fink WH. The dominant eye: its clinical significance. Arch Ophthal 1938; 19: 555-582

9. Porac C, Coren S. The dominant eye. Psychol Bull 1976; 83: 880-897

10. Mapp AP, Ono H, Barbeito R. What does the dominant eye dominate? A brief and somewhat contentious review. Percept Psychophys 2003; 65: 310-317

11. Coren S, Duckman RH. Ocular dominance and amblyopia. Am J Optom Physiol Opt 1975; 52: 47-50

12. Dornan J, Fernie GR, Holliday PJ. Visual input: Its importance in the control of postural sway. Arch Phys Med Rehabil 1978; 59: 586-591

13. Horak FB, Nashner LM, Diener HC. Postural strategies associated with somatosensory and vestibular loss. Exp Brain Res 1990; 82: 167-177

14. Shin YI, Kim YH, Kim NG. A quantitative assessment of static and dynamic postural sway in normal adults. J of Kosombe 1997; 18: 157-165

15. Ishizaki H, Pyykko I, Aalto H, Starck J. Repeatability and effect of instruction of body sway. Acta Otolaryngol 1991; 481: 589-592 